\title{
Strength from the Past: How Nostalgia and Self-Construal Affect Consumers' Willingness to Continue Participating in Sustainable Behaviors
}

\author{
Tao Le \\ School of Management, Jinan University, Guangzhou, China \\ Email: taolele996@126.com
}

How to cite this paper: Le, T. (2020). Strength from the Past: How Nostalgia and Self-Construal Affect Consumers' Willingness to Continue Participating in Sustainable Behaviors. American Journal of Industrial and Business Management, 10, 432-450. https://doi.org/10.4236/ajibm.2020.102029

Received: January 26, 2020

Accepted: February 22, 2020

Published: February 25, 2020

Copyright $\odot 2020$ by author(s) and Scientific Research Publishing Inc. This work is licensed under the Creative Commons Attribution International License (CC BY 4.0).

http://creativecommons.org/licenses/by/4.0/

\begin{abstract}
Solving environmental problems is important for the sustainable development of human beings. And consumers play a key role in solving environmental problems. However, there are many challenges in promoting consumers' participation in sustainable behaviors, such as "green fatigue", ego-others trade-off, and "long-term perspective". Starting from how to enable consumers to overcome challenges and participate more in sustainable behaviors, this research focused on the impact of cognition and emotion on sustainable consumption behaviors. More specifically, this research mainly explored how arousing consumers' nostalgia will affect their continuous participation in sustainable consumption behaviors. Through three studies, current research found that nostalgia affects consumers' willingness to participate in sustainable consumption behaviors, while nostalgia type and self-construal interact to influence consumers' willingness to participate in sustainable consumption behavior, and collective efficacy and personal efficacy play a mediation role respectively.
\end{abstract}

\section{Keywords}

Nostalgia, Self-Construal, Efficacy, Sustainable Consumption Behaviors

\section{Introduction}

Environmental issues are related to human sustainable development. On the one hand, the demand of natural resources has grown rapidly, and these resources have been overexploited; on the other hand, environmental pollution caused by human activities has become increasingly serious. In China, environmental is- 
sues have become one of the main factors restricting economic and social development and threatening people's health. Environmental problems are largely caused by human behavior, and especially depend on human sustainable behavior decisions.

However, encouraging consumers to engage in sustainable consumption, and in particular to encourage consumers to continue participating in sustainable consumption behaviors, actually faces many challenges. For example, participation in sustainable consumption behaviors first requires overcoming the self-other trade-off (White et al., 2019). At the same time, research has found that as climate change and other issues are serious and vague, they can have large-scale consequences that make individual actions seem trivial. This can lead to "green fatigue". And negative emotions will also be aroused due to information overload and lack of confidence in meaningful changes (Strother \& Fazal, 2011), and these negative emotions may demotivate consumers to persist.

Given the many challenges in promoting consumer participation in sustainable behaviors, how to overcome them has become the focus of scholars. Existing researches have focused on many impact factors like social impact, individual self, tangibility, the formation of habitual patterns, cognition and emotion, etc. (White et al., 2019). This study also starts with how to increase consumers' participation in sustainable behaviors, focusing on the impact of cognition and emotion on sustainable consumption behaviors. More specifically, this research is mainly exploring how stimulating consumer nostalgia can affect their continuing participating in sustainable consumption behaviors.

\section{Conceptual Background}

\subsection{The Impact of Nostalgia on Consumers' Continued Participation in Sustainable Consumption Behavior}

The Oxford Dictionary defines nostalgia as "the longing for the past." Hepper et al. (2012) believe that nostalgia is a complex emotion, involving past-oriented cognition. Familiar tastes, sounds, souvenirs, a conversation, or just a feeling of loneliness, can often trigger nostalgia. Nostalgic content mostly involves positive, meaningful personal experiences or a close relationship in childhood. With such memories, individuals will produce the desire to return to the past, and this desire to return to the past will be accompanied by complex emotions of happiness, longing and loss.

There are many positive effects of nostalgia on an individual's mental health and social behavior. Nostalgia serves four pivotal psychological functions: positive affect self-regard social connectedness existential meaning (Hepper et al., 2012). Based on the above four functions of nostalgia, prior researches found that nostalgia has a more widespread and universal impact. For example, nostalgia can reduce loneliness (Zhou et al., 2008) and promote prosocial behaviors (Zhou et al., 2012) because of social connectedness functions. Through a series of studies, researchers have found that nostalgia increases empathy for the bene- 
ficiaries of donations, making people kinder and more willing to donate (Zhou et al., 2012).

In addition, nostalgia can increase trust in and reduce prejudice against outgroup members. In one of the experiments, the researchers found that just letting people recall a nostalgic event that had a communication with a fat person would increase people's tolerance for obese outgroup members, increase trust in them, and thereby reduce Prejudice and discrimination against outgroup members (Turner, Wildschut, \& Sedikides, 2012).

Nostalgia can also mitigate the decline in organizational citizenship and cooperative behavior caused by procedural injustices. Procedural injustices in organizations often reduce social connections, which in turn reduces organizational citizenship and cooperative behavior of employees. Nostalgia mitigates the reduction in organizational citizenship and cooperative behavior due to procedural injustice by promoting perceived social connections (Van Dijke et al., 2015).

At the same time, previous researches suggested that collective nostalgia is a group-level emotion. Compared with personal nostalgia, collective nostalgia increases the recognition and support of a certain related group (Wildschut, Bruder, \& Robertson, 2014). Also, nostalgia may have a repairing effect. In other words, in addition to increasing self-esteem, it may also increase self-efficacy (Vess et al., 2012). Studies have shown that in social contexts, nostalgia can indeed enhance individuals' social self-efficacy to motivate them to achieve social goals (Abeyta et al., 2015). It is worth noting that some previous nostalgia research has suggested that nostalgia can positively affect sustainable consumption behaviors, such as stimulating nostalgia can increase people's charitable donations (Zhou, Wildschut, Sedikides, Shi, \& Feng, 2012). This is because charitable donations and sustainable consumption behaviors are both prosocial behaviors, of course, there are differences between the two. For example, charitable donations are altruistic prosocial behaviors, emphasizing attention to the interests of other individuals or a group, while sustainable consumption behaviors are compliance and public welfare-type prosocial behaviors, and more concerned about the overall interests of the public and even society (Li, Peng, Li, \& Ling, 2014). In terms of influencing factors of sustainable consumption behavior, past research has explored the impact of emotion on sustainable consumption behavior. For example, in terms of negative emotions, studies have shown that fear (Banerjee, Gulas, \& Iyer, 1995; Lowe et al., 2006; Li, 2014), guilt (Mallett, Melchiori, \& Strickroth, 2013; Muralidharan \& Sheehan, 2018; Onwezen, Antonides, \& Bartels, 2013) and grief (Sevillano, Aragones, \& Schultz, 2007; Schwartz \& Loewenstein, 2017) affect consumers' sustainable consumption behaviors, consumers can weaken these negative emotions by participating in sustainable consumption behaviors. Positive emotions such as "feelings of warm glow" (Giebelhausen et al., 2016), pleasure (Peter \& Honea, 2012), and pride (Bissing-Olson, Fielding, \& Iyer, 2016) will also promote consumers engage in sustainable consumption behavior in certain conditions. Nostalgia is a common emotional experience in to- 
day's era, and it is often used by companies for marketing. Current research suggested that nostalgia can affect consumers' willingness to participate in sustainable consumption. Based on the above analysis:

H1: Nostalgia influences consumers' willingness to continue participating in sustainable consumption behaviors.

\subsection{Types of Nostalgia and Self-Construal}

Nostalgia can increase consumers' willingness to continue participating in sustainable behaviors, but there are many types of nostalgia, so which kind of nostalgic stimulation can better strengthen consumers' willingness to continue to participate? In which context will it be more effective? This is the key concern of this research.

Self-construal is a very important part of the individual's self-system. They affect the individual's views on personal characteristics, Interpersonal relationships, the emotions that individuals experience in different situations, and the motivations that drive individuals to take action (Markus \& Kitayama, 1991). There are two self-construal: independent self-construal and interdependent self-construal (Markus \& Kitayama, 1991). In the field of consumer psychology and consumer behavior, studies have shown that self-construal affects individuals' cognition, emotions, motivations, and actions (Aaker \& Lee, 2001; Aaker \& Williams, 1998; Mandel, 2003; Monga \& John, 2008; Ng \& Houston, 2006). Once an individual's self-construal form is activated, subsequent self-related mental activities will be consistent with the activated self-construal form (Markus \& Kitayama, 1991) to achieve cognitive coordination. For example, for people with a high degree of independent self, they will be sensitive to important information about their attributes, appreciate the situation that allows individuals to express important internal attributes and confirm that individuals are independent, because individuals with high independent self emphasizes that themselves are Independent individuals, personal self-definition lies in their own characteristics, abilities and achievements; on the contrary, for people with a high degree of interdependent self, they will remain sensitive to important information about others and appreciate the kind of personal expression that is important to society, the commitment of the relationship, and the confirmation that the individual is connected with important others, because interdependence emphasizes that the individual is integrated with the situation, the self is defined in the interpersonal relationships, and they attaches importance to the situation, role, and obligation. Self-construal is closely related to the nostalgic experience, because nostalgia is a combination of psychological response and emotional investment (Schindler \& Holbrook, 2003). Nostalgia encourages individuals to recognize, recall, and even reconstruct the good times of the past to expand and create an ideal self (Belk, 1988). Nostalgia enables individuals to increase their self-support through identification with past experience, which indicates that nostalgia itself is a process of idealizing self. It is for this reason that the self-construal form of an individual 
will affect or even determine the self-image created by the individual through the nostalgic experience. According to the above analysis of personal nostalgia, collective nostalgia, independent self, and interdependent self, personal nostalgia mainly starts from the individual's own experience, focusing on the nostalgic emotions caused by the individual's past experience and life experience; the independent self emphasizes that the individual is an independent, the individuals with a high degree of independent self are sensitive to information about their own attributes, so for people with a high degree of independent self, they are more likely to indulge in personal nostalgia. In contrast, collective nostalgia is a group of people with the same culture, history, and life experience because they have similar memories and experiences. Collective nostalgia is based on relationship orientation and tends to social, cultural, generational, and group levels, emphasizing the connection between the individual and the past shared experience; while the interdependent self considers that the individual and the situation are integrated, the individuals with a high degree of interdependent self are sensitive to important information about others, so for people with a high degree of interdependent self, they are more likely to be immersed in collective nostalgia (Chai et al., 2011). In particular, how individuals view their self-construal may predict sustainable behavior. Self-construal can be used to measure individual differences and act as a starting psychological state (White, Argo, \& Sengupta, 2012). Some studies have also suggested that different self-construal can affect consumers' sustainable behavior (Arnocky, Stroink, \& DeCicco, 2007). In addition, some scholars have suggested that the activation of a broader and more transcendental self-construal which not only includes the self and others, but also other species and the biosphere may effectively increase environmental behavior (White et al., 2019). Based on the above analysis:

H2: The interaction between nostalgia and self-construal affects consumers' willingness to participate in sustainable consumption.

\subsection{Mediating Effect of Personal Efficacy and Collective Efficacy}

Previous researches have indicated that collective nostalgia is a group-level emotion. Compared with personal nostalgia, collective nostalgia increases identification and support for the certain related groups (Wildschut, Bruder, \& Robertson, 2014). Group identity is one of the most frequently mentioned concepts in the field of social psychology, and it reflects the degree to which individuals integrate group identity into self-construal. According to social identity theory, the higher the inner group identity of an individual, the more obvious the sociality in self-construal, and the stronger the psychological belonging to the inner group (Tajfel, 1982). Psychological belonging will cause individuals to have a more positive impression of ingroup (e.g., high perceived group effectiveness is a positive impression). Under this effect, the individual will emphasize the influence and appeal of ingroup. At the same time, a strong sense of identity will cause individuals to think that there are more similarities between members of the in- 
group and themselves in terms of goals, principles, values and beliefs, which will also affect the individual's awareness of group cohesion and cause them to feel that they unite within the ingroup. These feelings can in turn improve the individual's ability to evaluate the group, that is, it can improve the collective efficacy of group members (Koudenburg, Postmes, Gordijn, \& van Mourik Broekman, 2015). At the same time, it is worth noting that for people who have a high degree of interdependent self, they will be sensitive to important information about others and the collective, and appreciate the kind of situation that allows individuals to express their commitment to social relationships and confirm that individuals are interconnected with important others, because the interdependent self-construal emphasizes that the individual and the situation are integrated. The interdependent self is defined in the interpersonal relationship, and attaches importance to the situation, role, and obligations. Based on this, current research argues that for consumers with a high degree of interdependent self-construal, collective nostalgia can better stimulate their collective efficacy. Personal nostalgia can also promote an individual's sense of efficacy. Previous research has found that nostalgia may have a self-repairing function, that is, it may increase self-efficacy in addition to increasing self-esteem (Vess et al., 2012). At the same time, research in recent years showed that in social situations, personal nostalgia (such as recalling situations with children and playmates in childhood) can indeed enhance individuals' social self-efficacy to motivate them to achieve social goals (Abeyta et al., 2015). Based on the above analysis:

H3a: Personal efficacy mediates the interaction between personal nostalgia and independent self-construal on consumers' willingness to continue participating in sustainable consumption behaviors.

H3b: Collective efficacy mediates the interaction between collective nostalgia and interdependent self-construal on consumers' willingness to continue participating in sustainable consumption behaviors.

\section{Study 1}

The goal of study 1 is primarily testing hypothesis 1 , that is, exploding that whether nostalgia can affect consumers' willingness to participate in sustainable consumption behaviors.

\subsection{Procedure}

The experiment used a single factor design (nostalgia vs. control). Participants were recruited in online questionnaire platform "Wen Juanxing", participants completed the questionnaire online. The questionnaire contains a series of situational tasks and measurement of the variables this research focused on. These situational tasks and variable measurement are as following.

Participants first watched a video ad (nostalgia: Southern black sesame paste vs. control: Coca Cola advertisement). Pre-tests indicated that the nostalgia caused by the materials of the nostalgia group was significantly higher than that of the 
focus condition $\left(\mathrm{M}_{\text {nostalgia }}=5.15\right.$ vs. $\mathrm{M}_{\text {control }}=3.09, \mathrm{t}=21.85, \mathrm{df}=51, p<$ 0.01).The measuring of nostalgia is based on the scale developed by Pascal et al. (2002). After watching the video ad, the participants were told to complete a task. They can touch the "like" button for some pictures that are about a green campaign to support this green campaign. They viewed and liked these pictures in sequence, but these pictures could be "like" and viewed once. There were 25 pictures in the survey, while the participants can end viewing at any time and they didn't need to view and "like" all pictures. The number of "like" will be an index for measuring the willingness to participate. Finally, participants provided demographic characteristics, including age, gender and so on.

\subsection{Results}

A total of 60 participants were in the experiment (24 women and 36 men; the average age was 22 years old). In order to preliminary verify hypothesis 1 of current research, only 60 participants were recruited for this study 1 . And the sample size was enough for $\mathrm{T}$ test. Participants got paid after completing the experiment. The results showed that the number of "like" in the nostalgia group was significantly higher than that in the condition $\left(\mathrm{M}_{\text {nostalgia }}=15.16 \mathrm{vs} . \mathrm{M}_{\text {control }}=\right.$ $13.09, \mathrm{t}=21.85, \mathrm{df}=51, p<0.01)$. The hypothesis 1 was initially verified. The results of study 1 are shown in Figure 1 .

\subsection{Discussion of Results}

This experiment initially validated hypothesis 1 . However, nostalgia can increase consumers' willingness to continue to participate in sustainable behaviors, but there are many types of nostalgia, so which kind of nostalgic stimulation can better strengthen consumers' willingness to continue participating in sustainable consumption behaviors? In which context will it be more effective? At the same time, this experiment did not rule out the interference of some factors, such as the familiarity with the green campaign. This will be solved in study 2 .

\section{the number of "like"}



Figure 1. Study 1 results. 


\section{Study 2}

This experiment is mainly used to test whether the self-construal form of consumers and nostalgia have a joint effect on consumers' willingness of continuous participation in sustainable consumption behavior, that is, to verify hypothesis 2 .

\subsection{Procedure}

The experiment was 2 (nostalgia: personal nostalgia vs. collective nostalgia) $\times 2$ (self-construal: independent self vs. interdependent self) design, nostalgia and self-construal were manipulated through experimental stimuli. Participants were recruited in online questionnaire platform "Wen Juanxing". The questionnaire contains a series of situational tasks and measurement of the variables this research focused on. These situational tasks and variable measurement are as following.

First, participants were randomly divided into two groups and told that they were now participating in the evaluation of an advertisement. The advertisements were adapted from the experimental materials of Aaker and Williams (1998), Ng and Houston (2006), and experimental materials here were different from the materials in study 1 , and were used to manipulate participants' self-construal. After the participants watched the advertisement, they needed to fill out a scale for self-construal manipulation check (Aaker \& Lee, 2001). There were 6 items in total. 3 items of them were used to measure the degree to which the participants focus on others, and the rest were used to measure the degree to which the participants focus on themselves. In addition, the participants also needed to write down any associations about the advertisements. This task can be used to further strengthen the manipulation of self-construal and can also be used as supplementary materials for manipulation inspection.

Secondly, on the basis of self-construal manipulation, the participants in each group were randomly divided into two groups and told that a popular online green campaign, “Ant's Forest” in Ali Pay, had prepared a promotion article recently. The reason for choosing "Ant's Forest" in Ali Pay is that it has a high reputation among the young people. After viewing the advertisements, participants were asked to fill out a scale for nostalgia manipulation check (Pascal, Sprott, \& Muehling, 2002; Baker \& Kennedy, 1994; He, 2010). The scale consists of 14 items. Participants are required to evaluate the degree of agreement with the statement in the question according to their actual situation, and grade five points from 1 (completely disagree) to 5 (completely agree), including interpersonal nostalgia and family nostalgia. And personal nostalgia, this study divides nostalgia into personal nostalgia and collective nostalgia, so the interpersonal nostalgia and family nostalgia in this scale are combined into collective nostalgia. In addition, the participants also needed to write down any associations about the soft text, which can be used as supplementary materials for manipulation inspection.

In the measurement of willingness of continuous participation, the partici- 
pants were told to complete a task. Just like study 1, they can touch a "like" button for each picture that was about a green campaign to support this green campaign. This green campaign was "Ant's forest” in app "Ali Pay”, which is well-known in China. They viewed and liked these pictures in sequence, but these pictures could be "like" and viewed only once. There were 25 pictures in the survey, while the participants can end viewing at any time and they didn't need to view and "like" all pictures. The number of "like" will be an index for measuring the willingness to participate.

Control variables mainly measure participants' familiarity with keywords such as “Ant's Forest”, 2008 Olympic Games, and college entrance examination. There are 3 items in total. Demographic characteristics include age and gender.

\subsection{Results}

There were 124 participants in the experiment (60 women and 64 men; the average age was 23 years old). Participants got paid after completing the experiment.

\subsubsection{Control Variable}

Consistent with expectations, participants had a high degree of familiarity with "Ant's Forest" $(M=5.82)$. For the 2008 Olympic Games, the results also showed that participants had a high degree of familiarity $(M=5.93)$. Most of the participants were also familiar with the college entrance examination $(M=6.6)$. It can be seen that the participants have high familiarity with the experimental materials, indicating that it is appropriate to use them in this experiment. In addition, there were no significant differences in the familiarity of the participants with the "Ant's Forest" $(\mathrm{F}(3,122)=0.16, p>0.10)$ between four conditions. The participants' familiarity with the college entrance examination $(\mathrm{F}(1,61)=0.06, p>$ $0.10)$ and the 2008 Olympic events $(F(1,61)=1.17, p>0.10)$ were not significantly different either.

\subsubsection{Manipulation Check}

A 6-item scale (Aaker \& Lee, 2001) was used to check whether self-construal (the independent self-construal and interdependent self-construal) was successfully manipulated. 3 items of them were used to measure the degree to which the participants focus on friends (others) ( $\alpha=0.84$ ); and the other 3 items were used to measure the degree to which the participants focus on themselves $(\alpha=0.89)$. The results show that in the independent self-construal condition, the participants' degree of focus on themselves was significantly higher than their degree of focus on others $\left(\mathrm{M}_{\text {focus on themselves }}=5.15\right.$ vs. $\mathrm{M}_{\text {focus on others }}=3.09, \mathrm{t}=21.85, \mathrm{df}=62, p<$ $0.01)$; in interdependent self-construal condition, the degree that the participants focused on themselves was significantly lower than the degree that they focused on others $\left(\mathrm{M}_{\text {focus on themselves }}=3.03\right.$ vs. $\mathrm{M}_{\text {focus on others }}=4.97, \mathrm{t}=-17.84, \mathrm{df}=62, p<$ $0.01)$. It can be seen that the manipulation of self-construal was successful. At the same time, the analysis results of the participants' associations with advertising also supported this conclusion. 
In order to check the manipulation of personal nostalgia and collective nostalgia, participants were required to finished a 10-item measurement scale (Pascal, Sprott, \& Muehling, 2002; Baker \& Kennedy, 1994), of which 5 items were used to measure personal nostalgia $(\alpha=0.89$ ); The other 5 items are used to measure collective nostalgia $(\alpha=0.91)$. The data processing results showed that in the personal nostalgia condition, the personal nostalgia of the participants was significantly higher than the collective nostalgia $\left(\mathrm{M}_{\text {personal }}=5.04\right.$ vs. $\mathrm{M}_{\text {collective }}=$ $4.59, \mathrm{t}=19.26, \mathrm{df}=62, p<0.01)$; in the collective nostalgia condition, personal nostalgia was significantly lower than collective nostalgia $\left(\mathrm{M}_{\text {personal }}=5.12\right.$ vs. $\left.\mathrm{M}_{\text {collective }}=3.89, \mathrm{t}=-18.25, \mathrm{df}=62, p<0.01\right)$. All in all, the manipulation of nostalgic appeal was also successful, and qualitative data analysis on advertising association also supported this conclusion.

\subsubsection{Main Effects and Interaction}

Taking the number of touching "like" button for the pictures as the dependent variable, self-construal and nostalgia as independent variable, the result of two way ANOVA indicated that the main effect of nostalgia is significant $(\mathrm{F}(1,122)$ $=74.22, p<0.05)$; the main effect of self-construal is not significant $(\mathrm{F}(1,122)=$ $3.58, p>0.05)$.

The joint effect of self-construal and nostalgia on the number of touching the "like" button was significant $(\mathrm{F}(1,122)=78.96, p<0.01)$. The results are shown in Figure 2.

A further simple effect analysis found that in the independent self-construal condition, more participants liked the advertisement which is about personal nostalgia, compared with the collective nostalgic one $\left(\mathrm{M}_{\text {personal }}=17.71 \mathrm{vs.} \mathrm{M}_{\text {collective }}=\right.$ $14.49, \mathrm{~F}(1,61)=74.35, p<0.01)$; in the interdependent self-construal condition, more participants liked the advertisement which is about collective nostalgia, compared with the personal nostalgic one $\left(\mathrm{M}_{\text {personal }}=14.12 \mathrm{vs}\right.$. $\mathrm{M}_{\text {collective }}=16.33, \mathrm{~F}$ $(1,61)=63.35, p<0.01)$. It can be seen that H1b and H2b were supported.

\section{the number of "like"}

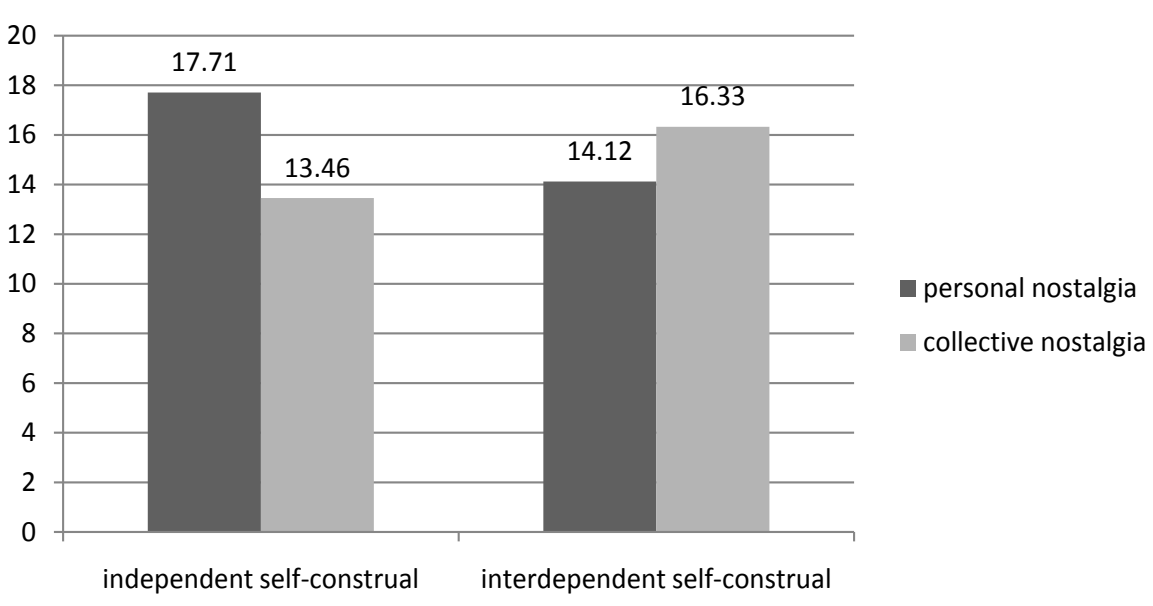

Figure 2. Study 2 results. 


\subsection{Discussion of Results}

The experimental results showed the self-construal form of consumers and nostalgia have a joint effect on consumers' willingness of continuous participation in sustainable consumption behavior. These results suggested that in environmental protection activities, nostalgic demands that perform well in one situation may not be effective in the other, and the self-construal form of consumers is a subdivision variable that enterprises should consider when adopting sustainable marketing (such as launching green products or initiating environmental protection activities).

Although the experimental results support the hypothesis, there are still some problems to be solved. First, what is the reliability of the experimental results? Secondly, the internal mechanism of this effect has not been explored. These problems will be solved in study 3 .

\section{Study 3}

Study 3 aimed to replicate the results of study 2 . The mechanism of the joint effect of self-construal and nostalgia on consumers' willingness of continuous participation in sustainable behavior will be explored in study 3 .

\subsection{Procedure}

The experiment uses 2 (nostalgia: personal nostalgia and collective nostalgia) $\times 2$ (self-construal: independent self and interdependent self) between subject design, nostalgia and self-construal were manipulated through experimental manipulation stimuli. Participants were recruited in online questionnaire platform "Wen Juanxing". The questionnaire contains a series of situational tasks and measurement of the variables this research focused on. These situational tasks and variable measurement are as following.

First of all, before the experiment started, the information on the questionnaire informed the participants that the study was a cognitive survey. Then, the self-construal of participants were manipulated, which was different from study 1 and study 2. In study 3, the method of "finding words" was used (Brewer \& Gardner, 1996) to start the type of self-construal of the participants. Participants were randomly divided into two conditions, each condition would read a different version of a travel journal, and were asked to circle all the personal pronouns, each of which was 20 . The difference between the two versions is the inadmissibility of personal pronouns. The personal pronouns of the independent self-construal condition are singular word "I", and the interdependent self-construal conditions are the plural word "we". After the word-finding task was completed, the participants completed the manipulation check, and the scale used to manipulation check was developed by Singelis (1994) and modified by Aaker (2000). Based on self-construal manipulation, the participants in each condition were randomly divided into two conditions again and informed that Company A had recently prepared an ecological environmental protection activity. To this end, they de- 
signed a text advertisement and wanted to hear consumers' opinions. Except that the company name and logo were virtual, the advertising used in study 3 was the same as the one used in study 2. Participants were then required to complete a nostalgia manipulation checks (Pascal, Sprott, \& Muehling, 2002; Baker \& Kennedy, 1994; He, 2010). The next step is the measurement of the mediation variable. The scale for measuring collective efficacy and self-efficacy were referenced from Van Zomeren (2013) and Bandura \& Locke (2003). This study was modified in accordance with the characteristics of the participants. Finally, the participants were required to complete measurement scales for dependent variable and control variables. The measurement of the willingness to continue participating in sustainable consumption behaviors was to touch a button to "like" the company A's environmental protection record pictures to support their environmental protection activities. There were 25 pictures, each of which can be "like" and viewed only once. At the same time, each picture provided an end button. Participants can end this part at any time, and at the beginning of this part, they were told that their "like" can support the environmental protection activities of company A. Finally, participants were asked to finished basic demographic characteristics.

\subsection{Results}

There were 116 students participating in study 3, including 52 women and 64 men; and the average age was 22 years old. Participants received corresponding compensation after completing the experimental questionnaire.

\subsubsection{Manipulation Check}

Experiment 3 used a different method to manipulate the self-construal of participants, the results indicated that the manipulation was successful. The independent self-construal score of the independent self-construal condition was significantly higher than the interdependent self-construal Score $\left(M_{\text {independent }}\right.$ self-construal $=5.16$ vs. $\mathrm{M}_{\text {interdependent self-construal }}=3.38, \mathrm{t}=31.22, \mathrm{df}=57, p<0.01$ ); the independent self-construal score of the interdependent self-construal condition was significantly lower than the interdependent self-construal score $\left(\mathrm{M}_{\text {independent }}\right.$ self-construal $=3.44$ vs. $\left.\mathrm{M}_{\text {interdependent self-construal }}=5.07, \mathrm{t}=-30.51, \mathrm{df}=57, p<0.01\right)$. And the results also showed that the different types of nostalgia were successfully manipulated. In the personal nostalgia condition, the personal nostalgia was significantly higher than the collective nostalgia $\left(\mathrm{M}_{\text {personal }}=5.01 \mathrm{vs} . \mathrm{M}_{\text {collective }}=3.72, \mathrm{t}\right.$ $=18.70, \mathrm{df}=57, p<0.01)$; in the collective nostalgia condition, the personal nostalgia was significantly lower than the virtual collective nostalgia $\left(\mathrm{M}_{\text {personal }}=\right.$ 3.42 vs. $\left.\mathrm{M}_{\text {collective }}=5.13, \mathrm{t}=-17.51, \mathrm{df}=57, p<0.01\right)$. All in all, nostalgic manipulations are also successful.

\subsubsection{Main Effects and Interaction}

Taking the number of touching "like" button for the pictures as the dependent variable, self-construal and nostalgia as independent variable, a two way ANOVA 
indicated that the main effect of nostalgia is significant $(\mathrm{F}(1,112)=71.92, p<$ $0.05)$; the main effect of self-construal is not significant $(\mathrm{F}(1,112)=2.98, p>$ 0.05). The joint effect of self-construal and nostalgia on the number of touching the "like" button for the pictures of company A's ecological environmental protection activities was significant $(\mathrm{F}(1,112)=73.56, p<0.01)$. The results of study 3 are shown in Figure 3.

A further simple effect analysis found that in the independent self-construal condition, more participants liked the advertisement which is about personal nostalgia, compared with the collective nostalgic one $\left(\mathrm{M}_{\text {personal }}=18.41 \mathrm{vs}\right.$. $\mathrm{M}_{\text {collec }}$ tive $=14.76, \mathrm{~F}(1,56)=77.38, p<0.01)$; in the interdependent self-construal condition, more participants liked the advertisement which is about collective nostalgia, compared with the personal nostalgic one $\left(\mathrm{M}_{\text {personal }}=13.33\right.$ vs. $\mathrm{M}_{\text {collective }}=$ $19.18, \mathrm{~F}(1,56)=33.35, p<0.01)$. It can be seen that $\mathrm{H} 1 \mathrm{~b}$ and $\mathrm{H} 2 \mathrm{~b}$ were supported again.

\subsubsection{Mediation}

To analyze the data regarding the mediation effect of personal efficacy and collective efficacy, study 3 used PROCESS, a regression-based approach developed by Hayes (2012). The sample size was selected as 5000 and the deviation correction method was adopted. The confidence interval was set as $95 \%$.

First, in order to verify the mediating effect of personal efficacy, personal efficacy was taken as a mediating variable, nostalgia type as an independent variable, self-construal type as a moderating variable, and the number of participants' "like" as a dependent variable. With a sample size of 5000, model 8 is selected for analyzing. The results showed that there was a confidence interval $[-1.5484$, -0.2527] for mediating effects, which was excluding 0 , indicating that mediating effects exist. Further results show that when the nostalgic type was personal nostalgia, the mediating effect of personal efficacy existed, with a confidence interval of $[-1.4332,-0.3244]$, excluding 0 , and the effect size is 0.8278 . When the nostalgic

\section{the number of "like"}

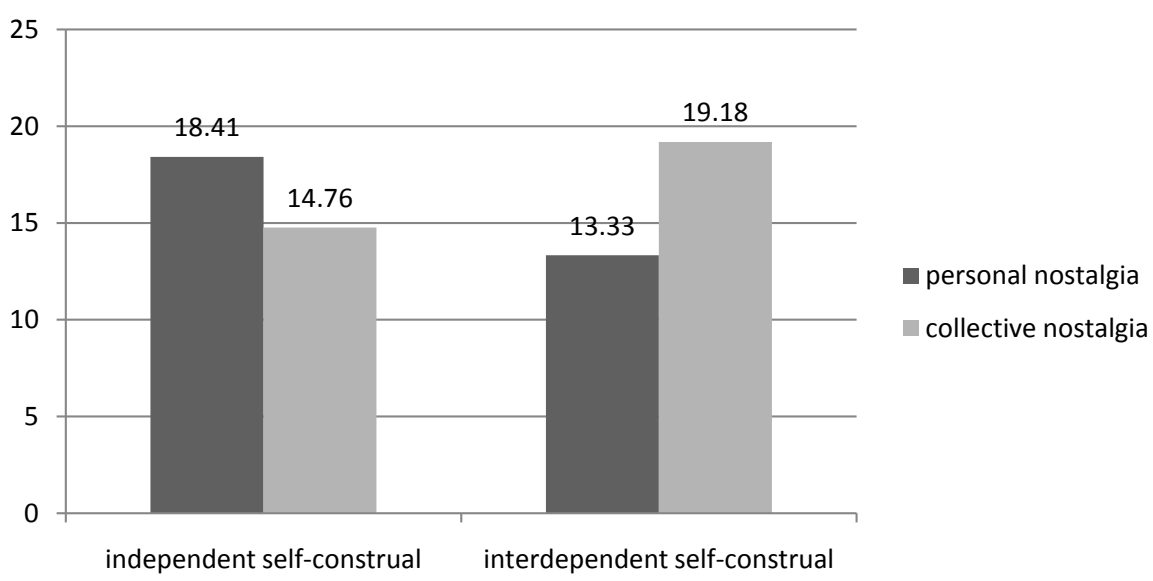

Figure 3. Study 3 results. 
type was collective nostalgia, the mediating effect of personal efficacy didn't exist. The confidence interval was $[-0.3241,0.4057]$, including 0 . The above results supported H3a.

In addition, in order to verify the mediating effect of collective efficacy, the collective efficacy was also taken as the mediating variable, nostalgia type was taken as the independent variable, and self-construal type acted as the moderating variable. At the same time, the number of participants' "like" still acted as a dependent variable. With a sample size of 5000 , model 8 is selected for analyzing. Finally, the results show that there was a confidence interval $[-1.1521,-0.1113]$ for mediating effects, excluding 0 , which indicated that mediating effects exist. Further results showed that when the nostalgic type was collective nostalgia, the mediating effect of collective efficacy existed, with a confidence interval of [0.3029, 1.1884 ], excluding 0 , and the effect size was 0.6745 . When the nostalgic type was personal nostalgia, collective efficacy had no mediating effect, and the confidence interval was $[-0.1954,0.4887]$, including 0 . The above results supported H3b.

\subsection{Discussion of Results}

Study 3 aimed to explode the mechanism of the joint effect of self-construal and nostalgia on consumers' willingness of continuous participation in sustainable behavior. The results of the study 3 indicated that when collective nostalgia and interdependent self-construal have a joint effect on the willingness to continue participating in sustainable consumption behaviors, collective efficacy plays a mediating role. However, when personal nostalgia and independent self-construal have a joint effect on the willingness to continue participating in sustainable consumption behaviors, personal efficacy plays a mediating role. At the same time, the experimental results of study 2 were replicated in study 3 .

\section{General Discussion}

\subsection{Theoretical Implications}

Some previous nostalgia researches have suggested that nostalgia can positively affect consumers' willingness to participate in sustainable consumption behaviors, such as stimulating nostalgia can increase people's charitable donations (Zhou, Wildschut, Sedikides, Shi, \& Feng, 2012). Both charitable donations and sustainable consumption behaviors are prosocial behaviors, so nostalgia seems to increase people's prosocial behavior. However, there are seemingly contradictory discoveries in the nostalgia field (Wang, Keh, \& Chao, 2018; Chen Rui, Chen Huihui, \& Zheng Yuhuang, 2017). For example, some studies have found that stimulating nostalgia will increase preferences for hedonic products (Chen Rui, Chen Huihui, \& Zheng Yuhuang, 2017), and nostalgia will also increase indulgent food consumption (Wang, Keh, \& Chao, 2018), and often hedonistic preferences Indulgent consumption is linked to low self-control, which seems to imply that nostalgia will weaken consumers' ability to control themselves in sus- 
tainable behaviors and thus negatively affect their participation in sustainable behaviors. So, can nostalgia promote consumers' continuous participation in sustainable consumption behavior? Current research pointed out that for consumers with different self-construal, different types of nostalgic content play different roles. Specifically, consumers with independent self-construal are more suitable to adopt personal nostalgic content to promote their willingness to continue participate in sustainable consumption behaviors, while consumers who have interdependent self-construal need to adopt collective nostalgic content.

Previous researches have explored the impact of emotions on sustainable consumer behavior. For example, in terms of negative emotions, studies have shown that fear (Banerjee, Gulas, \& Iyer, 1995; Lowe et al., 2006; Li, 2014), guilt (Mallett, Melchiori, \& Strickroth, 2013; Muralidharan \& Sheehan, 2018; Onwezen, Antonides, \& Bartels 2013) and grief (Sevillano, Aragones, \& Schultz 2007; Schwartz \& Loewenstein 2017) affects consumers' sustainable consumption behaviors. Positive emotions such as "feelings of warm glow" (Giebelhausen et al., 2016), pleasure (Peter \& Honea 2012), and pride (Bissing-Olson, Fielding, \& Iyer 2016) will also promote consumers engage in sustainable consumption behavior. Nostalgia is already a common emotional experience in today's era, and it is often used by companies for marketing. Whether nostalgia will increase consumers' continued participation in sustainable consumption behavior is worth exploring. Current research also enriched the researches on the influencing factors of sustainable consumption behavior.

\subsection{Managerial Implications}

In terms of marketing practice, nostalgia can improve people's sense of effectiveness, so for some sustainable consumption behaviors, such as the choice of green products, by triggering occasional nostalgic emotions may promote people's evaluation and purchase intention of green products. In addition, it is noted that nostalgic content types and consumers "self-construal can simultaneously affect their willingness to participate in sustainable consumption behaviors. Enterprises should pay attention to nostalgia when conducting activities. Nostalgic content types should match the participants" self-construal, or the self-construal can be started to match the nostalgic type. All of these can further enhance the consumer's willingness to participate.

\subsection{Limitations and Future Research}

Current research explored how nostalgia affects consumers' willingness to continue participating in sustainable consumption behaviors. However, there are still many limitations in this research, which can be further improved in future study.

First, the coverage of the sample can be extended. The participants in 3 studies were undergraduates and graduate students. The structure of participants was simple. This part can be improved in future research. 
Second, the experimental materials and manipulation methods can be improved. 3 studies in current research collected data by simulating consumption scenarios in reality. However, the experiments in current research did not last for a long time, especially for the measurement of continuous participation willingness. This part can be improved in future research.

Finally, the choice of mediation variables and moderators should be further deepened. In view of the limitation of the research, only personal efficacy, collective efficacy, and type of self-construal were chosen as mediating and moderating variables, but there may be other mediating effects on them in practice. And some factors also have certain effects, such as consumers' nostalgic tendencies. Therefore, in the future research, the influence of other possible psychological mechanisms can be explored.

\section{Conflicts of Interest}

The author declares no conflicts of interest regarding the publication of this paper.

\section{References}

Aaker, J. L. (2000). Accessibility or Diagnosticity? Disentangling the Influence of Culture on Persuasion Processes and Attitudes. Journal of Consumer Research, 26, 340-357. https://doi.org/10.1086/209567

Aaker, J. L., \& Lee, A. Y. (2001). "I" Seek Pleasures and "We" Avoid Pains: The Role of Self-Regulatory Goals in Information Processing and Persuasion. Journal of Consumer Research, 28, 33-49. https://doi.org/10.1086/321946

Aaker, J. L., \& Williams, P. (1998). Empathy versus Pride: The Influence of Emotional Appeals across Cultures. Journal of Consumer Research, 25, 241-261. https://doi.org/10.1086/209537

Abeyta, A. A., Routledge, C., Roylance, C., Wildschut, T., \& Sedikides, C. (2015). Attachment-Related Avoidance and the Social and Agentic Content of Nostalgic Memories. Journal of Social and Personal Relationships, 32, 406-413. https://doi.org/10.1177/0265407514533770

Arnocky, S., Stroink, M., \& DeCicco, T. (2007). Self-Construal Predicts Environmental Concern, Cooperation, and Conservation. Journal of Environmental Psychology, 27, 255-264. https://doi.org/10.1016/j.jenvp.2007.06.005

Baker, S. M., \& Kennedy, P. F. (1994). Death by Nostalgia: A Diagnosis of Context-Specific Cases. Advances in Consumer Research, 21, 169-174.

Bandura, A., \& Locke, E. A. (2003). Negative Self-Efficacy and Goal Effects Revisited. Journal of Applied Psychology, 88, 87-99. https://doi.org/10.1037/0021-9010.88.1.87

Banerjee, S., Gulas, C. S., \& Iyer, E. (1995). Shades of Green: A Multidimensional Analysis of Environmental Advertising. Journal of Advertising, 24, 21-31. https://doi.org/10.1080/00913367.1995.10673473

Belk, R. W. (1988). Possessions and the Extended Self. Journal of Consumer Research, 15, 139-168. https://doi.org/10.1086/209154

Bissing-Olson, M. J., Fielding, K. S., \& Iyer, A. (2016). Experiences of Pride, Not Guilt, Predict Pro-Environmental Behavior When Pro-Environmental Descriptive Norms Are More Positive. Journal of Environmental Psychology, 45, 145-153. 
https://doi.org/10.1016/j.jenvp.2016.01.001

Brewer, M. B., \& Gardner, W. (1996). Who Is This "We"? Levels of Collective Identity and Self Representations. Journal of Personality and Social Psychology, 71, 83-93. https://doi.org/10.1037/0022-3514.71.1.83

Chai, J. W., Zhao, G. Z., \& Zhang, Z. L. (2011). Impact of Self-Construal on the Effectiveness of Different Nostalgia Appeals. Acta Psychologica Sinica, 43, 308-321. https://doi.org/10.3724/SP.J.1041.2011.00308

Chen, R., Chen, H. H., \& Zheng, Y. H. (2017). The Impact of Nostalgia on Consumers' Choice between Hedonic and Utilitarian Products. Nankai Business Review, 20, 140-149.

Giebelhausen, M., Chun, H. H., Cronin Jr., J. J., \& Hult, G. T. M. (2016). Adjusting the Warm-Glow Thermostat: How Incentivizing Participation in Voluntary Green Programs Moderates Their Impact on Service Satisfaction. Journal of Marketing, 80, 56-71. https://doi.org/10.1509/jm.14.0497

Hayes, A. F. (2012). PROCESS: A Versatile Computational Tool for Observed Variable Mediation, Moderation, and Conditional Process Modeling.

He, J. X. (2010). How Do We Miss the Past? Development and Comparative Verification of the Consumer Nostalgia Tendency Scale in the Context of Chinese Culture. Journal of Marketing Science, 10, 30-50.

Hepper, E. G., Ritchie, T. D., Sedikides, C., \& Wildschut, T. (2012). Odyssey’s End: Lay Conceptions of Nostalgia Reflect Its Original Homeric Meaning. Emotion, 12, 102-119. https://doi.org/10.1037/a0025167

Koudenburg, N., Postmes, T., Gordijn, E. H., \& van Mourik Broekman, A. (2015). Uniform and Complementary Social Interaction: Distinct Pathways to Solidarity. PLoS ONE, 10, e0129061. https://doi.org/10.1371/journal.pone.0129061

Li, A., Peng, Y., Li, B., \& Ling, W. (2014). The Effects of Money Priming on Pro-Social Behavior and Its Decision Mechanism. Advances in Psychological Science, 22, 845-856. https://doi.org/10.3724/SP.J.1042.2014.00845

Li, S. C. S. (2014). Fear Appeals and College Students' Attitudes and Behavioral Intentions toward Global Warming. The Journal of Environmental Education, 45, 243-257. https://doi.org/10.1080/00958964.2014.930399

Lowe, T., Brown, K., Dessai, S., de França Doria, M., Haynes, K., \& Vincent, K. (2006). Does Tomorrow Ever Come? Disaster Narrative and Public Perceptions of Climate Change. Public Understanding of Science, 15, 435-457. https://doi.org/10.1177/0963662506063796

Mallett, R. K., Melchiori, K. J., \& Strickroth, T. (2013). Self-Confrontation via a Carbon Footprint Calculator Increases Guilt and Support for a Pro-Environmental Group. Ecopsychology, 5, 9-16. https://doi.org/10.1089/eco.2012.0067

Mandel, N. (2003). Shifting Selves and Decision Making: The Effects of Self-Construal Priming on Consumer Risk-Taking. Journal of Consumer Research, 30, 30-40. https://doi.org/10.1086/374700

Markus, H. R., \& Kitayama, S. (1991). Culture and the Self: Implications for Cognition, Emotion, and Motivation. Psychological Review, 98, 224-253. https://doi.org/10.1037/0033-295X.98.2.224

Monga, A. B., \& John, D. R. (2008). When Does Negative Brand Publicity Hurt? The Moderating Influence of Analytic versus Holistic Thinking. Journal of Consumer Psychology, 18, 320-332. https://doi.org/10.1016/j.jcps.2008.09.009

Muralidharan, S., \& Sheehan, K. (2018). The Role of Guilt in Influencing Sustainable Pro-Environmental Behaviors among Shoppers: Differences in Response by Gender to 
Messaging about England's Plastic-Bag Levy. Journal of Advertising Research, 58, 349-362. https://doi.org/10.2501/JAR-2017-029

Ng, S., \& Houston, M. J. (2006). Exemplars or Beliefs? The Impact of Self-View on the Nature and Relative Influence of Brand Associations. Journal of Consumer Research, 32, 519-529. https://doi.org/10.1086/500482

Onwezen, M. C., Antonides, G., \& Bartels, J. (2013). The Norm Activation Model: An Exploration of the Functions of Anticipated Pride and Guilt in Pro-Environmental Behaviour. Journal of Economic Psychology, 39, 141-153.

https://doi.org/10.1016/j.joep.2013.07.005

Pascal, V. J., Sprott, D. E., \& Muehling, D. D. (2002). The Influence of Evoked Nostalgia on Consumers' Responses to Advertising: An Exploratory Study. Journal of Current Issues \& Research in Advertising, 24, 39-47. https://doi.org/10.1080/10641734.2002.10505126

Peter, P. C., \& Honea, H. (2012). Targeting Social Messages with Emotions of Change: The Call for Optimism. Journal of Public Policy \& Marketing, 31, 269-283. https://doi.org/10.1509/jppm.11.098

Schindler, R. M., \& Holbrook, M. B. (2003). Nostalgia for Early Experience as a Determinant of Consumer Preferences. Psychology \& Marketing, 20, 275-302. https://doi.org/10.1002/mar.10074

Schwartz, D., \& Loewenstein, G. (2017). The Chill of the Moment: Emotions and Pro-Environmental Behavior. Journal of Public Policy \& Marketing, 36, 255-268. https://doi.org/10.1509/jppm.16.132

Sevillano, V., Aragonés, J. I., \& Schultz, P. W. (2007). Perspective Taking, Environmental Concern, and the Moderating Role of Dispositional Empathy. Environment and Behavior, 39, 685-705. https://doi.org/10.1177/0013916506292334

Singelis, T. M. (1994). The Measurement of Independent and Interdependent Self-Construals. Personality and Social Psychology Bulletin, 20, 580-591. https://doi.org/10.1177/0146167294205014

Strother, J. B., \& Fazal, Z. (2011). Can Green Fatigue Hamper Sustainability Communication Efforts? In 2011 IEEE International Professional Communication Conference (pp. 1-6). IEEE. https://doi.org/10.1109/IPCC.2011.6087206

Tajfel, H. (1982). Social Psychology of Intergroup Relations. Annual Review of Psychology, 33, 1-39. https://doi.org/10.1146/annurev.ps.33.020182.000245

Turner, R. N., Wildschut, T., \& Sedikides, C. (2012). Dropping the Weight Stigma: Nostalgia Improves Attitudes toward Persons Who Are Overweight. Journal of Experimental Social Psychology, 48, 130-137. https://doi.org/10.1016/j.jesp.2011.09.007

Van Dijke, M., Wildschut, T., Leunissen, J. M., \& Sedikides, C. (2015). Nostalgia Buffers the Negative Impact of Low Procedural Justice on Cooperation. Organizational Behavior and Human Decision Processes, 127, 15-29. https://doi.org/10.1016/j.obhdp.2014.11.005

Van Zomeren, M., Saguy, T., \& Schellhaas, F. M. (2013). Believing in "Making a Difference" to Collective Efforts: Participative Efficacy Beliefs as a Unique Predictor of Collective Action. Group Processes \& Intergroup Relations, 16, 618-634. https://doi.org/10.1177/1368430212467476

Vess, M., Arndt, J., Routledge, C., Sedikides, C., \& Wildschut, T. (2012). Nostalgia as a Resource for the Self. Self and Identity, 11, 273-284. https://doi.org/10.1080/15298868.2010.521452

Wang, X., Keh, H. T., \& Chao, C. H. (2018). Nostalgia and Consumer Preference for In- 
dulgent Foods: The Role of Social Connectedness. International Journal of Consumer Studies, 42, 316-326. https://doi.org/10.1111/ijcs.12419

White, K., Argo, J. J., \& Sengupta, J. (2012). Dissociative versus Associative Responses to Social Identity Threat: The Role of Consumer Self-Construal. Journal of Consumer Research, 39, 704-719. https://doi.org/10.1086/664977

White, K., Habib, R., \& Hardisty, D. J. (2019). How to SHIFT Consumer Behaviors to Be More Sustainable: A Literature Review and Guiding Framework. Journal of Marketing, 83, 22-49. https://doi.org/10.1177/0022242919825649

Wildschut, T., Bruder, M., Robertson, S., van Tilburg, W. A., \& Sedikides, C. (2014). Collective Nostalgia: A Group-Level Emotion That Confers Unique Benefits on the Group. Journal of Personality and Social Psychology, 107, 844-863. https://doi.org/10.1037/a0037760

Zhou, X., Sedikides, C., Wildschut, T., \& Gao, D. G. (2008). Counteracting Loneliness: On the Restorative Function of Nostalgia. Psychological Science, 19, 1023-1029. https://doi.org/10.1111/j.1467-9280.2008.02194.x

Zhou, X., Wildschut, T., Sedikides, C., Shi, K., \& Feng, C. (2012). Nostalgia: The Gift That Keeps on Giving. Journal of Consumer Research, 39, 39-50. https://doi.org/10.1086/662199 